\title{
Role of Serum Uric Acid in Assessment of Rectal Cancer Metastasis
}

\author{
Amany H. Lashin ${ }^{\text {a }}$, Hala M. El-feky ${ }^{\text {a }}$, Gada A. Abd El-Fattah ${ }^{\text {b }}$, Dalia T. Khoziem ${ }^{\text {c }}$
}

a Department of Hepatology, Gastroenterology and Infectious diseases, Benha Faculty of Medicine, Benha University, Egypt. b Department of Pathology, Benha Faculty of Medicine, Benha University, Egypt. c Department of Hepatology, Gastroenterology and Infectious diseases ,Sohag Cancer Institute, Egypt.

Correspondence to: Dalia T. Khoziem, Department of Hepatology, Gastroenterology and Infectious diseases ,Sohag Cancer Institute , Egypt

\begin{abstract}
:
Background: Colorectal cancer is the third most common noncutaneous malignancy, and accounts for the second most frequent cause in cancer-related deaths. Early detection and diagnosis of cancer rectum and its metastasis is very helpful in treatment and prognosis ,so that accurate laboratory markers have been needed to monitoring tumor recurrence, metastasis, and prognosis. Aim: The aim of this study was to investigate the role of uric acid (UA) in assessing rectal cancer metastasis. Patients and methods: Two hundred newly diagnosed patients with cancer rectum were included in our study and divided into two groups, one with metastasis and the other without metastasis. Results: There were statistical significant differences regarding CA19.9, carcinoembryonic antigen (CEA), and C-reactive protein (CRP) between the 2 groups. Importantly, serum concentrations of UA in patients with lymphatic metastasis were found to be increased compared with those without metastasis $(7.08 \pm 2.45$ vs $4.30 \pm 1.12 ; \mathrm{P}<0.0001)$.
\end{abstract}

There were positive correlations between serum UA and CRP, CA199 and CEA $(\mathrm{r}=0.27, \mathrm{P}=0.0001 ; \mathrm{r}=0.28, \mathrm{P}=0.0001 ; \mathrm{r}=0.29, \mathrm{P}=0.0001)$ in rectal cancer patients with metastasis. Multivariate analysis model revealed that CEA, CA19.9 , CRP, ESR ( 1st , 2nd hours) ,serum uric acid, presence of ascites, Perirectal fat plane, Degree of tumor differentiation, and $\mathrm{T}$ classification, Duke's stage, total protein ,TLC and ALT level were the predictors of rectal cancer metastasis. ROC curve analysis revealed that AUC of serum UA was 0.82 , with sensitivity of 63.0 and specificity of 95.0. for prediction of metastasis in rectal cancer patients. Conclusion: Serum UA may be a useful marker in assessing tumor metastasis in patients with rectal cancer. Keywords: carcino-embryonic antigen, rectal cancer, serum uric acid, tumor metastasis. 


\section{Introduction}

Colorectal cancer is the third most common non-cutaneous malignancy, and accounts for the second most frequent cause in cancer-related deaths [1].

Adenoma is a developmental stage of rectal cancer, which is a progress from the adenoma carcinoma sequence to invasive cancer, and inflammation may play a key role in metastasis of rectal cancer [2].

Oncologists have been aware that, compared with colon tumor, the diagnosis, staging and, treatment for rectal cancer have significant difference. Fortunately, local control and survival rate in colorectal cancer has been significantly improved with the improvement of operation and chemotherapy $[3,4]$.

Laboratory, the levels of carcino-embryonic antigen (CEA) have severed as an independent prognostic factor in rectal cancer patients [5].

Several inflammatory biomarkers are valuable and easily available for the assessment of prognosis in patients with rectal cancer such as tumor necrosis factor (TNF), interleukin
(IL)-6, and C-reactive protein (CRP) [6].

Moreover, CRP has been involved with recurrence and prognosis in patients with rectal cancer [7]. However, other laboratory markers also have been needed to monitor tumor recurrence, metastasis, and prognosis

Uric acid (UA) is the end product of purine metabolism in the body. In the past, previous study focused on the relationship between UA and gout. Recently, serum UA was found to be associated with various diseases, such as cardiovascular disease, acute ischemic stroke, and lung cancer $[\mathbf{8 , 9 , 1 0 ]}$ and increased serum UA concentrations were associated with mortality of cardiovascular disease [11].

In fact, serum UA has been regarded to be an antioxidant in the body, and presents a compensatory mechanism against inflammation [12].

A cross-sectional study found that elevated UA concentrations were not a risk factor of colorectal adenoma; but is a risk indicator for metabolic syndrome-related colorectal adenoma [13]. 
In spite of that, uric acid serves as a "danger signal" released from dying cells (potentially including cancer cells) and could promote anti-cancer immunity, but the acute and chronic inflammation of gout could contribute to a pro-cancer environment [14].

\section{Patients and methods}

\section{Participants and materials}

This longitudinal study was conducted upon 200 adult patients who were diagnosed with rectal cancer and did not received chemo or radiotherapy yet at Sohag cancer institute during the period from January 2016 to 2018.

The study protocol was evaluated by ethical committee of Benha Faculty of Medicine and its University Hospitals and approval for the study was obtained also from Sohag cancer institute before involvement in the study. Informed consent was obtained from each patient or his/her relative.

\section{Data collection}

Studied cases were divided into two groups, group 1 with metastasis and group 2 without metastasis. All patients were subjected to history taking. ,complete clinical examinations, routine laboratory investigation [complete blood count (CBC), blood group, fasting blood sugar, total protein , ALT, AST , serum albumin ,serum total and direct bilirubin , hepatitis markers, serum creatinine ,blood Urea,(CEA), CA19.9 - C-reactive protein - ESR first and second hours], serum uric acid levels were measured at the time of diagnosis and after the 3rd month of chemotherapy . Also imaging studies (including abdominopelvic ultrasound, abdominal $\mathrm{CT}$ and barium enema), colonoscopy and histopathological records were done for the studied cases.

\section{Statistical analysis}

Data was analyzed using STATA version 12.1 (Stata Statistical Software: Release 14.2 College Station, TX: StataCorp LP.). Quantitative data was represented as mean, standard deviation, median and range. Data was analyzed using student t-test to compare means of two groups. When the data was not normally distributed Kruskal Wallis test for comparison of three or more groups and Mann-Whitney test was used to compare two groups. Wilcoxson signed rank test was used to compare uric acid level before and after chemotherapy. Qualitative data was presented as number 
and percentage and compared using either Chi square test or fisher exact test. Spearman's correlation analysis was used to detect correlation between uric acid and other inflammatory and tumor markers. Roc curve analysis was used to detect best cutoff of different variables that predict metastatic rectal cancer. Sensitivity, specificity, positive predicted value and negative predictive value were also calculated. Odds ratios were obtained from logistic regression analysis. Graphs were produced by using Excel or STATA program. p value was considered significant if it was less than 0.05 .

\section{RESULTS}

No statistical significant difference was detected between two groups of cancer rectum regarding sex and age. fig (1).

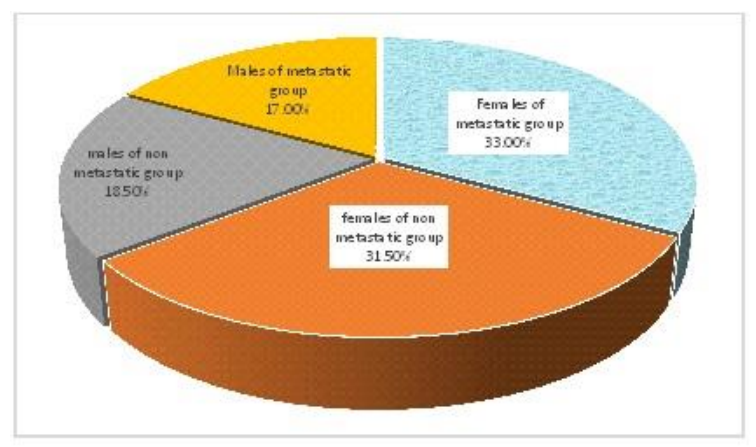

Figure (1): percentage of gender among the studied cases

There were statistical significant differences regarding CA19.9, carcino-embryonic antigen (CEA), and CRP between the 2 groups. Importantly, serum UA concentrations in patients with lymphatic metastasis (fig. 2) were found to be increased compared with patients without lymphatic metastasis $(7.08 \pm 2.45 \mathrm{mg} / \mathrm{dL}$ vs $4.30 \pm 1.12 \mathrm{mg} / \mathrm{dL} ; \quad \mathrm{P}<0.0001)$ table (1). Among the studied cases, significant positive correlations were found between serum UA levels before chemotherapy administration on one hand and CEA, CA19.9, CRP levels and number of lymph nodes affection on the other hand ( $\mathrm{r}=0.27$, $\mathrm{P}=0.0001 ; \quad \mathrm{r}=0.28, \quad \mathrm{P}=0.0001 ; \quad \mathrm{r}=0.29$, $\mathrm{P}=0.0001 ; \mathrm{r}=0.65, \mathrm{P}<0.0001)$ table (2).

Multivariable analysis showed that CEA, CA19.9 , C-reactive protein, ESR ( 1st , 2nd hours), serum uric acid, presence of ascites, perirectal fat plane, degree of tumor differentiation, and T classification, Duke's stage, total serum protein, TLC and ALT level were the predictors of rectal cancer metastasis table (3).

The present study revealed that serum UA level was significantly correlated with CRP, CEA, CA19.9 and lymphatic metastasis $(\mathrm{P}<0.0001)$.

ROC curve analysis (fig. 3); revealed that serum UA had sensitivity of $63.0 \%$ and 
specificity of $95.0 \%$ with AUC of 0.82 in assessing metastasis in rectal cancer patients. CRP at cutoff ( $\geq 3.6)$ combined with uric acid at cutoff ( $\geq 6.1 \mathrm{mg} / \mathrm{dL}$ ) had $(\geq 6.1 \mathrm{mg} / \mathrm{dL})$ had AUC 0.78 with $61.5 \%$ sensitivity, $97.5 \%$ specificity, $71.9 \%$ NPV and $96.3 \%$ PPV. On the other hand ,CEA at cutoff $(\geq 365)$ when combined with Uric acid at cutoff $(\geq 6.1 \mathrm{mg} / \mathrm{dL})$ it had AUC 0.77 with $72.0 \%$ sensitivity, $74.5 \%$ specificity, high $73.0 \% \mathrm{NPV}$ and $77.8 \%$ PPV table (4). accuracy of 0.81 , sensitivity $64.5 \%$, specificity $92.5 \%$, NPV $72.3 \%$ and PPV $89.7 \%$. While the combination of CA19.9 at cutoff $(\geq 434)$ with uric acid at cutoff Lastly when ESR 2nd hours at cutoff ( $\geq 40$ $\mathrm{mm} / \mathrm{hr}$ ) combined with Uric acid at cutoff $(\geq 6.1 \mathrm{mg} / \mathrm{dL})$ the AUC was 0.75 with sensitivity $77.5 \%$, specificity $70.5 \%$, NPV $78.6 \%$ and PPV $77.8 \%$ table (4).

Table ( 1) : Inflammatory, Tumor Markers and Uric Acid Levels among the Studied Groups

\begin{tabular}{|c|c|c|c|}
\hline Variable & $\begin{array}{c}\text { Metastatic group } \\
\quad(\mathbf{n}=100)\end{array}$ & $\begin{array}{l}\text { Non-metastatic } \\
\text { group }(n=100)\end{array}$ & $P$ value \\
\hline \multicolumn{4}{|l|}{ CEA (ng/ml) } \\
\hline Mean \pm SD & $718.10 \pm 415.75$ & $389.63 \pm 341.23$ & $<0.0001$ \\
\hline Median (range) & $658.7(22-1478)$ & $333(8-1000)$ & \\
\hline \multicolumn{4}{|l|}{ CA199(u/ml) } \\
\hline Mean \pm SD & $1112.75 \pm 2453.42$ & $124.70 \pm 98.81$ & $<0.0001$ \\
\hline Median (range) & $576(10-23602)$ & $87.5(5.1-434)$ & \\
\hline \multicolumn{4}{|l|}{$\mathrm{C}$ reactive protein $(\mathrm{mg} / \mathrm{l})$} \\
\hline Mean \pm SD & $5.55 \pm 2.88$ & $3.13 \pm 1.49$ & $<0.0001$ \\
\hline Median (range) & $4.4(2.8-12)$ & $3.0(2.0-8.0)$ & \\
\hline \multicolumn{4}{|l|}{ ESR $1^{\text {st }}$ hours (mm/hour) } \\
\hline Mean \pm SD & $20.78 \pm 5.52$ & $18.65 \pm 5.28$ & 0.006 \\
\hline Median (range) & $20(6-39)$ & $20(7-32)$ & \\
\hline \multicolumn{4}{|l|}{ ESR $2^{\text {nd }}$ hours (mm/hour) } \\
\hline Mean \pm SD & $64.6 \pm 24.18$ & $48.73 \pm 19.47$ & \\
\hline Median (range) & $60(11-122)$ & $46.5(16-93)$ & $<0.0001$ \\
\hline \multicolumn{4}{|l|}{ Uric acid before CTH(mg/dl) } \\
\hline Mean \pm SD & $7.08 \pm 2.45$ & $4.30 \pm 1.12$ & \\
\hline Median (range) & $7.25(2.3-11.3)$ & $4.2(2.46-5)$ & $<0.0001$ \\
\hline \multicolumn{4}{|l|}{ Uric acid after 3months of CTH(mg/dl) } \\
\hline Mean \pm SD & $8.47 \pm 2.18$ & $4.15 \pm 1.11$ & \\
\hline Median (range) & $8.35(3.7-12.5)$ & $4(2.2-7.5)$ & $<0.0001$ \\
\hline $\begin{array}{l}\text { *CEA (carcinembryonic antigen) } \\
\text { *ESR (erythrocyte sedimentation rare) } \\
{ }^{*} \text { CTH (chemotherapy) }\end{array}$ & $\begin{array}{l}* \text { CA19, } 9 \text { (carbol } \\
* \text { UA (uric acid) }\end{array}$ & antigen19,9) & \\
\hline
\end{tabular}


Benha medical journal vol.37, Special issue (Internal medicine and Hepatology), 2020

Table ( 2) : Correlation between Baseline (Before Chemotherapy) Serum UA Levels and Inflammatory, Tumor Markers and Number of LN Involved

\begin{tabular}{|c|c|c|}
\hline Variable & Correlation coefficient (r) & $P$ value \\
\hline CEA & 0.27 & 0.0001 \\
\hline CA19,9 & 0.28 & 0.0001 \\
\hline $\mathrm{C}$ reactive protein & 0.29 & 0.0001 \\
\hline ESR $1^{\text {st }}$ hours & 0.01 & 0.84 \\
\hline ESR $2^{\text {nd }}$ hours & 0.21 & 0.003 \\
\hline Number of $\mathbf{L N}$ & 0.65 & $<0.0001$ \\
\hline Lymphocyte ratio & -0.03 & 0.63 \\
\hline
\end{tabular}

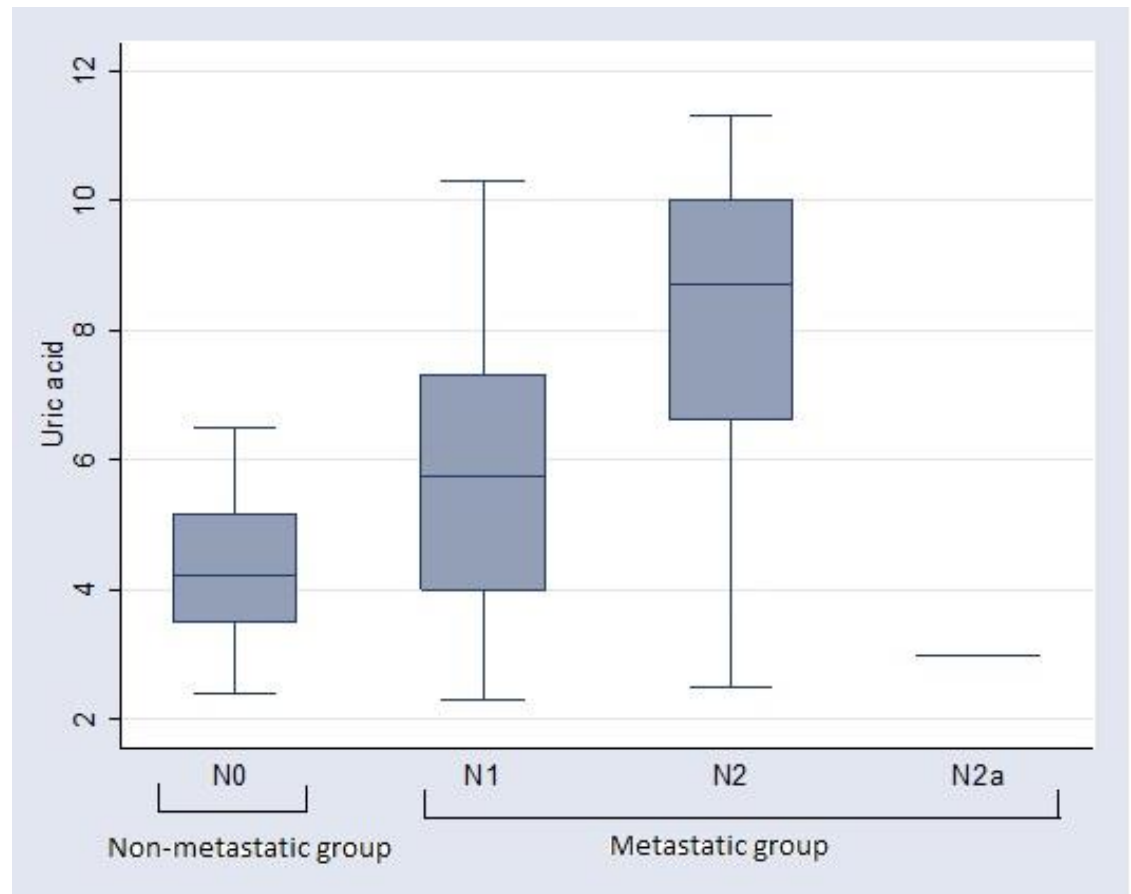

fig. 2: serum UA concentrations in patients with lymphatic metastasis compared with patients without lymphatic metastasis 
Table ( 3) : Multiple Logistic Regression Analysis for Predictors of Metastatsis in Rectal Cancer

\begin{tabular}{|c|c|c|}
\hline Variable & Odds ratio ( $95 \%$ confidence interval) & P value \\
\hline Grade & $3.803(2.023-7.151)$ & 0.000 \\
\hline Degree of differentiation & $2.958(1.936-4.519)$ & 0.000 \\
\hline Perirectal fat plane & $2.01(1.42-2.86)$ & 0.000 \\
\hline Total protein & $0.296(0.159-0.550)$ & 0.000 \\
\hline Uric acid & $2.06(1.49-2.83)$ & $<0.0001$ \\
\hline $\mathrm{C}$ reactive protein & $1.82(1.37-2.43)$ & $<0.0001$ \\
\hline Ascites & $4.5(1.90-10.89)$ & 0.001 \\
\hline CA19,9 & $1.004(1.001-1.007)$ & 0.001 \\
\hline CEA & $1.002(1.001-1.003)$ & 0.005 \\
\hline ESR $1^{\text {st }}$ hours & $1.076(1.020-1.136)$ & 0.007 \\
\hline Duke's stage & $1.812(1.61-2.058)$ & 0.008 \\
\hline T classification & $1.512(1.11-2.058)$ & 0.009 \\
\hline ALT & $1.027(1.004-1.050)$ & 0.019 \\
\hline ESR $2^{\text {nd }}$ hours & $1.03(1.01-1.06)$ & 0.02 \\
\hline TLC & $0.879(0.788-0.980)$ & 0.021 \\
\hline Neutrophil & $0.979(0.956-1.002)$ & 0.075 \\
\hline M classification & $0.77(0.5720-1.036)$ & 0.085 \\
\hline Size of mass by CT & $1.118(0.833-1.501)$ & 0.454 \\
\hline Blood group & $0.961(0.866-1.066)$ & 0.459 \\
\hline МCHC & $1.047(0.88-1.243)$ & 0.595 \\
\hline
\end{tabular}

Table (4) :combination between inflammatory, tumor markers and uric acid for predicting metastatic rectal cancer

\begin{tabular}{ccccccccc}
\hline $\begin{array}{l}\text { Diagnostic } \\
\text { accuracy } \%\end{array}$ & $\begin{array}{l}\text { NPP } \\
\%\end{array}$ & $\begin{array}{l}\text { PPV } \\
\%\end{array}$ & Specificity $\%$ & Sensitivity \% & $\begin{array}{l}\text { Best cut } \\
\text { off point }\end{array}$ & P value & AUC & Combination \\
\hline 73.2 & 73.0 & 77.8 & 74.5 & 72 & $\geq 365$ & $<0.0001$ & 0.77 & CEA and UA \\
79.7 & 71.9 & 96.3 & 97.5 & 61.5 & $\geq 434$ & $<0.0001$ & 0.78 & $\begin{array}{r}\text { CA199 and UA } \\
78.5\end{array}$ \\
\hline 72.3 & 89.7 & 92.5 & 64.5 & $\geq 3.6$ & $<0.0001$ & 0.81 & $\begin{array}{r}\text { C reactive } \\
\text { protein and UA }\end{array}$ \\
& 78.0 & 77.8 & 70.5 & 77.5 & $\geq 40$ & $<0.0001$ & 0.75 & $\begin{array}{r}\text { ESR 2nd hours } \\
\text { and UA }\end{array}$ \\
\hline
\end{tabular}




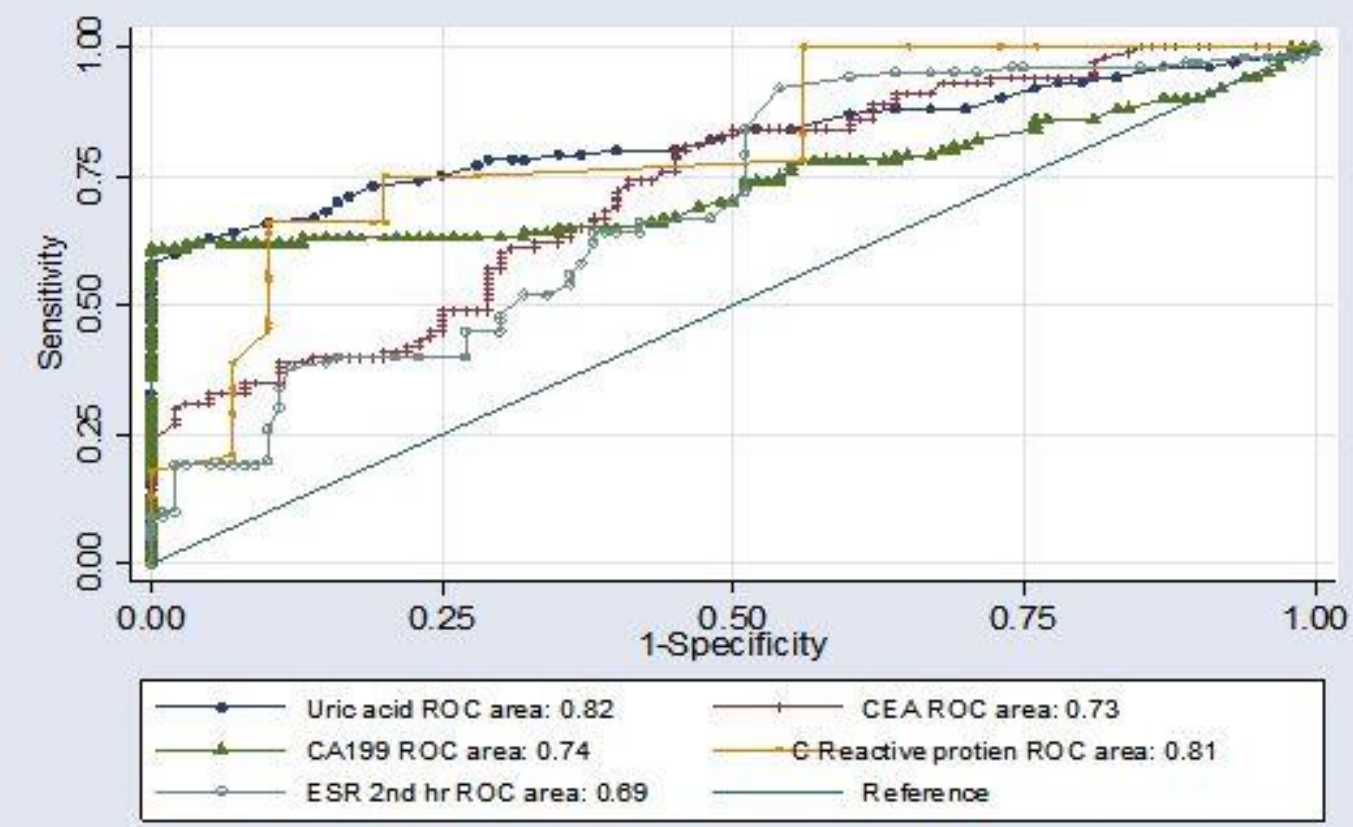

\section{Discussion}

Several inflammatory biomarkers are valuable and easily available for the assessment of prognosis in patients with rectal cancer however, other laboratory markers also have been needed to monitor tumor recurrence, metastasis, and prognosis[6,7].

In this study, we found that there were high statistical significant differences between patients with metastatic and nonmetastatic cancer rectum regarding CEA,CA19.9 ,ESR $2^{\text {nd }}$ hour, (UA) before and 3months after chemotherapy and statistical significant difference between them regarding ESR $1^{\text {st }}$ hour, These results were in agreement with the study done by
Ahmet Ozan Cetin et al., [15] and Cheng Yuan et al., [16] who found that serum UA, CEA, CA19.9 and CRP was increased in rectal cancer patients with metastasis compared with those without metastasis. Also these results were in agreement with that done by Ruo-Han Tseng et al., [17] \& Hentrich et al .,[18] and F.Selcukbiricik et al ., [19] who found that patients with metastatic colorectal cancer who had received bevacizumab therapy showing significant increases of serum uric acid as a part of tumor lysis syndrome.

In the current study, statistically significant positive correlations were 
detected between serum UA levels before chemotherapy administration on one hand and CEA,CA19.9, CRP and number of lymph nodes affection on other hand. These results were in agreement with the study done by Ahmet Ozan Cetin et al ., [15] and Cheng Yuan et al., [16] who found that serum UA, CEA, CA19.9 and CRP was increased in rectal cancer patients with metastasis compared with those without metastasis and observed that serum UA concentrations were positively correlated with CRP and CEA level in rectal cancer patients with metastasis. This may be due to the presence of more severe inflammatory response that may contribute to increased serum UA concentration in rectal cancer patients with metastasis.

The present work found non-significant correlation between serum uric acid levels before chemotherapy administration and ESR 1st hours and neutrophil / lymphocyte ratio ,these results were in disagreement with Ahmet Ozan Cetin et al., [15] and Mehmet Artaç et al .,[20] who reported that preoperative $\mathrm{N} / \mathrm{L}$ ratio was a prognostic factor in CRC . But, this was in disagreement with the study of Walsh et al [21] who concluded that preoperative $\mathrm{N} / \mathrm{L}$ ratio greater than 5 was correlated with overall and cancer-specific survival in univariate analysis. Again it disagreed with the study of Mehmet Artaç1 et al., [20] who studied 90 patients with CRC, aimed to investigate prognostic impact of neutrophil/lymphocyte ratio, platelet count, CRP, and serum albumin levels in metastatic Colorectal Cancer patients treated with FOLFIRI-Bevacizumab and found that $47 \%$ of patients with $\mathrm{N} / \mathrm{L}$ ratio $>2.5$ showed progressive disease versus 43 $\%$ in patients with $\mathrm{N} / \mathrm{L}$ ratio $<2.5$ $(p$ value $=0.025)$. This difference may be due to difference in number of patients of both studies and due to different effect of chemotherapy on neutrophils.

Multiple logistic regression analysis of this study revealed that CEA, CA19.9 , Creactive protein, ESR ( 1 st , 2nd hours), serum uric acid, presence of ascites, perirectal fat plane, degree of tumor differentiation, $\mathrm{T}$ classification, Duke's stage, total protein ,TLC and ALT level were the predictors of rectal cancer metastasis . These results were in agreement with the study of Ahmet Ozan Cetin et al [15] who studied 150 patients with stage II and III colorectal adenocarcinoma and found that increased serum uric acid level was significantly positively correlated with 
stage IIA and stage IIIB $(r=0.598, p=0.029)$, N3 disease, $(\mathrm{r}=0.618, \mathrm{p}=0.024)$, grade III tumor $(\mathrm{r}=0.631, \mathrm{p}=0.029)$, presence of weight loss $(r=0.539, p=0.037)$, presence of lymphovascular invasion $\quad(\mathrm{r}=0.621$, $\mathrm{p}=0.031$ ), recurrence with other organ metastases $(\mathrm{r}=0.648, \mathrm{p}=0.018)$, baseline platelet counts $(\mathrm{r}=0.496, \mathrm{p}=0.042)$, baseline CEA levels $(\mathrm{r}=0.509, \mathrm{p}=0.036)$, baseline CA19.9 levels ( $\mathrm{r}=0.645, \mathrm{p}=0.028)$, and a shorter disease-free survival rates $(r=0.651$, $\mathrm{p}=0.018$, which is considered as a the predictors of rectal cancer stage II and III (stages of cancer rectum with metastasis).

This study shows that statistical significant positive correlation was detected between metastatic rectal cancer on one hand and serum uric acid and C-reactive protein level on other hand (Odds ratio 2.06-1.82 and $\mathrm{p}$ value $<0.0001$ and $<0.0001$ respectively), also significant positive correlations were between CEA, CA199 and ESR 2nd hours levels and rectal cancer metastasis (Odds ratio 1.002 -1.004and1.03 and $\mathrm{p}$ value 0.0 respectively). These results coincided with study done by Cheng Yuan et al [16] who found that elevated serum levels of UA were significant prognostic marker for lymphatic metastasis in patients with rectal cancer, independently of CRP,
CEA, and tumor diameter (odds ratio [OR] $1.035,95 \%$ confidence interval [CI] 1.013$1.057, \mathrm{P}=0.002)$. Another study conducted by Ahmet Ozan Cetin et al [15] revealed that increased serum uric acid level was positively correlated with stage IIA and stage IIIB ( $r=0.598, p=0.029), \mathrm{N} 3$ disease, $(\mathrm{r}=0.618, \quad \mathrm{p}=0.024), \quad$ grade III tumor $(\mathrm{r}=0.631, \mathrm{p}=0.029)$, presence of weight loss $(\mathrm{r}=0.539, \quad \mathrm{p}=0.037), \quad$ presence of lymphovascular invasion $\quad(\mathrm{r}=0.621$, $\mathrm{p}=0.031$ ), recurrence with liver metastases $(\mathrm{r}=0.648, \mathrm{p}=0.018)$, baseline platelet counts $(\mathrm{r}=0.496, \mathrm{p}=0.042)$, baseline CEA levels $(\mathrm{r}=0.509, \mathrm{p}=0.036)$, baseline CA19-9 levels $(\mathrm{r}=0.645, \mathrm{p}=0.028)$, and a shorter diseasefree survival rates $(\mathrm{r}=0.651, \mathrm{p}=\mathrm{ROC}$ curve analysis revealed that serum UA had sensitivity of $63.0 \%$ and specificity of 95.0 $\%$ with AUC of 0.82 in assessing metastasis in rectal cancer patients 0.018).

Yuan et al. [16] reported that serum UA had sensitivity of 0.864 and specificity of 0.739 in assessing metastatic rectal cancer patients, results that .

In the current study, there are, however, several limitations. First, a relatively small sample size in this study is a major limitation. Moreover, some confounders associated with UA, such as diet, exercise, 
were not included as variables in multiple regression analysis, and more clinical parameters for the severity of the disease were needed to explain the relationship between serum UA and metastasis status in multiple regression analysis. Despite these limitations, our results suggest that serum UA may be a useful marker in assessing tumor metastasis in patients with rectal cancer.

\section{Ethical review:}

The study was approved by the Ethics Committee of Benha Faculaty of Medicine and its University Hospitals and approval for the study was obtained also from Sohag cancer institute before involvement in the study, informed consent was obtained from each patients or his/her relative.

\section{References}

[1] Siegel RL, Miller KD, Jemal A. (2015): Cancer statistics, Cancer J Clin, 65:5-29.

[2] Shah MS, Fogelman DR, Raghav KP, (2015): Joint prognostic effect of obesity and chronic systemic inflammation in patients with metastatic colorectal cancer. Cancer. 121:2968-2975.

[3] Sauer R, Becker H, Hohenberger W, Rödel C, Wittekind C, Fietkau R, et al. (2004): Preoperative versus postoperative chemoradiotherapy for rectal cancer. N Engl J Med. 351:1731-1740.
[4] Sebag-Montefiore D, Stephens RJ, Steele R, Monson J, Grieve R, Khanna S ,et al. (2009): Preoperative radiotherapy versus selective postoperative chemoradiotherapy in patients with rectal cancer (MRC CR07 and NCIC-CTG C016): a multicentre, randomised trial. Lancet (London, England) .373:811-820.

[5] Huang CS, Lin JK, Wang LW, Liang WY, Lin CC, Lan YT, et al. (2014): Assessment of the value of carcinoembryonic antigen reduction ratio as a prognosis factor in rectal cancer. Am $\mathbf{J}$ Surg;208:99-105.

[6] Zhou B, Shu B, Yang J, Liu J, Xi T, Xing Y, et al. (2014): C-reactive protein, interleukin-6 and the risk of colorectal cancer: a meta-analysis. Cancer Causes Control ;25:1397- 1405.

[7] Toiyama Y, Inoue Y, Saigusa S, Kawamura M, Kawamoto A. (2013): C-reactive protein as predictor of recurrence in patients with rectal cancer undergoing chemoradiotherapy followed by surgery. Anticancer Res;33:5065-5074.

[8] Horsfall LJ, Nazareth I, Petersen I. (2014): Serum uric acid and the risk of respiratory disease: a population-based cohort study. Thorax ;69:1021-1026.

[9] Wu AH, Gladden JD, Ahmed M, Ahmed A, Filippatos G (2016): Relation of serum uric acid to cardiovascular disease. Int J Cardiol ;213:4-7.

[10] Wang Z, Lin Y, Liu Y, Chen Y, Wang B, Li C, et al.(2016): Serum uric acid levels and outcomes after acute ischemic stroke. Molec Neurobiol;53:1753-1759. 
[11] Wu CY, Hu HY, Chou YJ, Huang N, Chou YJ, Li CP, et al.2015: High serum uric acid levels are associated with all-cause and cardiovascular, but not cancer mortality in elderly adults. J Am Geriatr Soc;63:1829-1836.

[12] Nieto FJ, Iribarren C, Gross MD ,Comstock GW,Cutler RG. (2000): Uric acid and serum antioxidant capacity: a reaction to atherosclerosis? Atherosclerosis; 48:131-139.

[13] Kim HJ, Kim JE, Jung JH, Kim ER, Hong SN, Chang DK, et al. (2015): Uric acid is a risk indicator for metabolic syndrome-related colorectal adenoma: results in a korean population receiving screening colonoscopy. Kor J Gastroenterol ;66:202-208.

[14] Robbins AS, Siegel RL, Jemal A. (2012): Racial disparities in stage-specific colorectal cancer mortality rates from 1985 to 2008. J Clin Oncol.; 30(4):401-5. [Medline].

[15] Ahmet Ozan Cetin, Muhyettin Omar, Serkan Calp, Hasan Tunca, Nevin Yimaz and Burak Ozseker(2017); Hyperuricemia at The Time Of Diagnosis is a Factor for Poor Prognosis in Patients With Stage II and III Colorectal Cancer (Uric Acid and Colorectal Cancer) DOI:10.22034/APJCP.2017.18.2.485

[16] Cheng Yuan, MMa, Xin-Hua Xu, MMb , XiaoLong Wang, MDc et al. (2016): Relationship between serum uric acid and metastatic and nonmetastatic rectal cancer patients with undergoing no chemotherapy Medicine; 95:47
[17] Ruo-Han Tseng a, Ching-Hsu Wu a, Kuan-Lin Wu b, Guan-Min Lai a, Jen-Tsun Lin. (2016): Tumor lysis syndrome in a patient with metastatic colon cancer after treatment with oxaliplatin and 5Fu Journal of Cancer Research and Practice 3 $124 \mathrm{e} 127$

[18] Hentrich M, Schiel X, Scheidt B. (2008): Tumor lysis syndrome after irinotecan/5-FU/folinic acid/bevacizumab-containing therapy in a patient heavily pretreated for metastatic colon cancer. Acta Oncol. ;47:155e156.

[19] F. Selcukbiricik ,M. Kanbay, Y. Solak, A. Bilici,M. Kanıtez,E. Balık et al, (2016): Serum uric acid as a surrogate marker of favorable response to bevacizumab treatment in patients with metastatic colon cancer.Clin Transl Oncol; 18:1082-1087

[20] Mehmet Artaç \& Mükremin Uysal \& Mustafa Karaağaç \& Levent Korkmaz \&Zehra Er \& Tunç Güler et al,(2017) , Prognostic Impact of Neutrophil/Lymphocyte Ratio, Platelet Count, CRP, and Albumin Levels in Metastatic ColorectalCancer Patients Treated with FOLFIRI-Bevacizumab J Gastrointest Canc 48:176-180DOI 10.1007/s120292016-9879-4

[21] Walsh SR, Cook EJ, Goulder F, Justin TA, Keeling NJ. (2005): Neutrophil lymphocyte ratio as a prognostic factor in colorectal cancer. J SurgOncol. 2005;91:181-184.

Availablefrom:http://www.ncbi.nlm.nih.gov/pubmed /16118772.

To cite this article: Amany H. Lashin, Hala M. El-feky, Gada A. Abd El-Fattah, Dalia T. Khoziem. Role of Serum Uric Acid in Assessment of Rectal Cancer Metastasis. BMFJ 2020; 37 (Internal medicine and Hepatology): 12-23. DOI: 10.21608/bmfj.2019.14570.1014 
Original article 